\section{Commentary: Let's re-examine the system, not the surgeon: Addressing the need for cardiothoracic surgery resident involvement in quality improvement}

\author{
Jacqueline K. Olive, BA, ${ }^{\mathrm{a}}$ and \\ Tom C. Nguyen, MD, FACS, FACC ${ }^{\text {b,c }}$
}

To err is human, yet by evaluating our mistakes and developing solutions, we can reduce further harm and improve outcomes for our future patients. In this issue of the Journal, Moffatt-Bruce and colleagues discuss the role of the cardiothoracic (CT) surgery resident in quality improvement (QI) and the value that this work adds to an individual's training, institution, and specialty at large. ${ }^{1}$ The authors cite ongoing formalized QI curriculums from which surgery residents have been able to address common postoperative complications, such as surgical-site infections and permanent pacemaker implantation after transcatheter aortic valve replacement; to develop leadership skills; and to improve their institutions' rankings. They additionally offer numerous suggestions for implementation, including competitions, symposiums, scholarships, and faculty-supported projects. We commend the authors for their innovative vision for self-directed learning during CT surgery residency.

At the frontline of patient care, CT surgery residents are the most qualified to lead QI, and rightfully should also serve as key stakeholders in the conversations that transform training paradigms. Often the topics at hand directly relate to the resident's experience, from balancing resident autonomy and supervision to reducing duty hour oversight and burnout. More than previous generations, "millennial"

\footnotetext{
From the ${ }^{\mathrm{a} B a y l o r}$ College of Medicine; ${ }^{\mathrm{b}}$ Department of Cardiothoracic and Vascular Surgery, University of Texas Health Science Center Houston, McGovern Medical School; and ${ }^{\mathrm{c}}$ Memorial Hermann Heart and Vascular Institute, Houston, Tex.

Disclosures: Dr Nguyen is consultant for Edwards LifeSciences. Ms Olive has nothing to disclose with regard to commercial support.

Received for publication March 18, 2020; revisions received March 18, 2020; accepted for publication March 20, 2020; available ahead of print April 6, 2020. Address for reprints: Tom C. Nguyen, MD, FACS, FACC, 6400 Fannin St, Suite 2850,

Houston, TX 77030 (E-mail: tom.c.nguyen@gmail.com).

J Thorac Cardiovasc Surg 2020;160:1261-2

$0022-5223 / \$ 36.00$

Copyright (c) 2020 by The American Association for Thoracic Surgery

https://doi.org/10.1016/j.jtcvs.2020.03.077
}

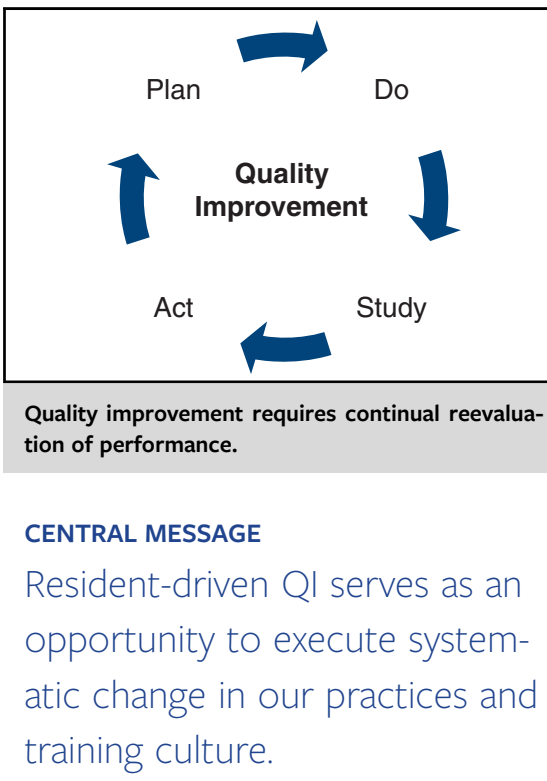

residents desire creative methods of instruction and a multifaceted training experience that emphasizes problem-solving and team-based growth. ${ }^{2}$

For decades, the morbidity and mortality (M\&M) conference has brought mistakes to light in a public forum, promoting open discussion necessary in complex and technical surgical fields. However, each M\&M conference widely varies in content and structure and all too often serves as a subjective, and perhaps punitive, learning experience for residents. ${ }^{3}$ In contrast, QI initiatives standardize individual error and may instead empower residents to transform their mistakes into tangible improvements.

Any cultural shift takes time, which unfortunately is a precious commodity for CT surgery residents. Although the Accreditation Council for Graduate Medical Education stipulates that residents be able to critically analyze the care they provide to achieve organizational patient safety goals, it is a concern that the formal implementation of QI into the curriculum may paradoxically increase resident fatigue and medical errors. ${ }^{4} \mathrm{CT}$ surgery residency is already much longer than most other residencies. As institutions shift toward condensing rather than lengthening the training period, the unequivocal priority must remain on equipping residents with the technical skills and clinical judgment honed from a full case load. This priority is especially important, as more procedures rely on newer transcatheter and minimally invasive techniques. Furthermore, additional bureaucratic 
oversight may divert vital resources and expertise away from these immediate clinical needs.

Although participation in QI adds another competing demand to the CT surgery resident's busy schedule, it is obvious that the burgeoning field of surgical QI delivers value beyond the scope of operating room instruction and $M \& M$ conferences, with groups such as MoffattBruce and colleagues leading the way. ${ }^{5}$ As the future of CT surgery faces an increasing demand for services and a shortage of surgeons, we must address errors from a birds-eye view to foster a greater culture of safety and accountability.

\section{References}

1. Moffatt-Bruce SD, Lee M, Kneuertz P. Quality improvement in cardiothoracic surgery residency: training in the culture of change. J Thorac Cardiovasc Surg. 2020; 160:1255-60.

2. Barmparas G, Imai TA, Gewertz BL. The millennials are here and they expect more from their surgical educators! Ann Surg. 2019;270:962-3.

3. Bohnen JD, Chang DC, Lillemoe KD. Reconceiving the morbidity and mortality conference in an era of big data: an "unexpected" outcomes approach. Ann Surg. 2016;263:857-9.

4. Common Program Requirements; . Available at: https://www.acgme.org/WhatWe-Do/Accreditation/Common-Program-Requirements. Accessed March 16, 2020.

5. Milojevic M, Bond C, Theurer PF, Jones RN, Dabir R, Likosky DS, et al. The role of regional collaboratives in quality improvement: time to organize, and how? Semin Thorac Cardiovasc Surg. 2020;32:8-13.
See Article page 1255 .

\section{Commentary: The power of qi: Teaching future surgeons about quality improvement and generating momentum for a culture of change}

Jules Lin, MD

In this issue of the Journal, Moffatt-Bruce and colleagues ${ }^{1}$ discuss the importance of training cardiothoracic surgery residents on quality improvement. Participation in patient safety activities is now a required component of residency training, ${ }^{2}$ and aspects of quality improvement and patient safety are reflected in more than $40 \%$ of milestones from 26 residency programs across all specialties. ${ }^{3}$ Including residents in quality improvement initiatives is essential, since they are responsible for the delivery and documentation of

From the Section of Thoracic Surgery, Department of Surgery, University of Michigan Medical Center, Ann Arbor, Mich.

Disclosures: The author reported no conflicts of interest.

The Journal policy requires editors and reviewers to disclose conflicts of interest and to decline handling or reviewing manuscripts for which they may have a conflict of interest. The editors and reviewers of this article have no conflicts of interest.

Received for publication April 21, 2020; accepted for publication April 21, 2020; available ahead of print May 4, 2020.

Address for reprints: Jules Lin, MD, Section of Thoracic Surgery, 1500 E. Medical Center Dr, 2120TC/5344, Ann Arbor, MI 48109-5344 (E-mail: juleslin@umich. edu).

J Thorac Cardiovasc Surg 2020;160:1262-3

0022-5223/\$36.00

Copyright $(92020$ by The American Association for Thoracic Surgery

https://doi.org/10.1016/j.jtcvs.2020.04.092
Check for updates

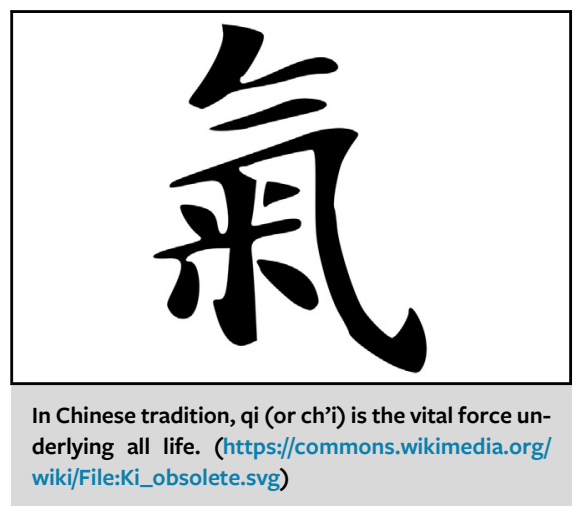

CENTRAL MESSAGE

As health systems shift to value-

based care, teaching our resi-

dents to incorporate quality

improvement into practice is

essential if we are to adapt and

generate momentum for a cul-

ture of change.

frontline care in most academic centers. Engaging residents in quality improvement resulted in improved documentation and a reduction in patient length of stay. ${ }^{4}$ A quality improvement project using an algorithm outlining indications for testing was also able to change medical resident test ordering behavior and prevented unnecessary downstream testing leading to a decrease in costs. ${ }^{5}$

Moffatt-Bruce and colleagues argue that cardiothoracic residents are uniquely positioned, due to the complexity of cardiothoracic surgery with a dependence on 